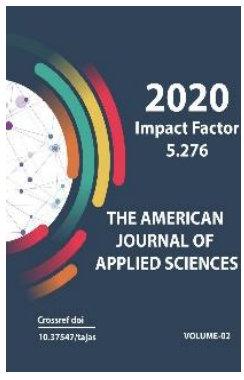

Journal Website: http://usajournalshub.c om/index,php/tajas

Copyright: Original content from this work may be used under the terms of the creative commons attributes 4.0 licence.

\section{Speech Etiquette In The Language Picture Of The World}

\author{
Umida Amirjanovna Alibaeva \\ Senior Lecturer, Languages Department, Academy of the Armed Forces of the Republic of \\ Uzbekistan
}

Shokhnoza Panjievna Imamova

Associate Professor, Languages Department, Academy of the Armed Forces of the Republic of Uzbekistan

Sanjar Khasanovich Rakhmanov

Academy of the Armed Forces of the Republic of Uzbekistan

\title{
ABSTRACT
}

The article describes the meanings and features of speech etiquette. Etiquette and speech etiquette have been also analyzed.

Etiquette is a set of rules of conduct, ensuring the maintenance of the perceptions of suitable manners and a manner of courtesy and mutual respect in a society provided.

\section{KEYWORDS}

Etiquette, speech etiquette, speaking, greetings, culture, art.

\section{INTRODUCTION}

The style of communication with people is always considered a direct sign of a person's level of upbringing. In order to be a worthy member of society, one should form communication skills in oneself, in the absence of which it will be very difficult in modern society.
The formation of a culture of communication skills and abilities is a long-term and difficult process. It is based on several goals and objectives, having achieved which, you can fully master the skill of tactful and respectful communication with people in a secular society and at home. They are aimed at developing the following qualities: 
- Sociability as an individual personality trait;

- The formation of communicative relationships in society;

- Lack of isolation from society;

- Social activity;

- improving academic performance;

National differences in speech etiquette in different states and national features of speech etiquette.

\section{MAIN PART}

One of the important assets of the people is culture and speech etiquette, which do not exist without each other. Any state has its own ethical generally recognized norms and rules of communication. In some cases, they may look strange and unusual to humans.

Speech etiquette is a significant component of any state culture. In the language, speech behavior, stable communication formulas, a rich folk skill, individuality of customs, lifestyle, everyday life of any nation was deposited. And this is infinitely valuable.

The national peculiarity of speech etiquette in any state is very striking, due to the fact that the inimitable features of the language here, as we see, are superimposed on the characteristic features of rituals, habits, everything accepted and unaccepted in behavior, permissible and prohibited in social etiquette. Sometimes in the most sudden way, national-cultural characteristics of the speech behavior of speakers are expressed.

Each culture has its own speech formulas, based on the origins of the nation and state itself. They reflect the formed folk habits and customs, as well as the attitude of society towards men and women.

There are many examples of the state peculiarities of speech and non-speech behavior of various peoples in communicative moments. Any person who finds himself in a particular republic or country immediately notices such features.

The culture of any nation is unique, and it finds its own manifestation in all spheres of people's life, speech etiquette is also no exception.

In the broadest sense of the word, speech etiquette characterizes almost any successful act of communication. Therefore, speech etiquette is associated with the so-called postulates of speech communication, which make possible and successful interaction of communication participants.

For example, the national features of speech etiquette, one can cite the peculiarity of Russian speech etiquette, namely, the presence in it of two pronouns - "you" and "you", which can be evaluated as forms of the 2nd singular. The choice of this or another form depends on the social status of the interlocutors, the nature of their relationship, the official / unofficial situation. Addressing "you" is not accepted in any way with unknown people; in an official situation; with elders, positions. At the same time, "you" does not need to be addressed to friends, classmates or work colleagues.

Speech etiquette is a set of requirements for the form, content, order, character and situational relevance of statements adopted in a given culture. The famous researcher of speech etiquette N.I. Formanovskaya gives the following definition: "Speech etiquette is understood as the regulating rules of speech behavior, a system of nationally specific stereotyped, stable communication formulas, adopted and prescribed by society to establish contact with interlocutors, maintain and interrupt contact in the chosen tone."

Speech etiquette, in particular, includes words and expressions used by people for parting, requests, apologies, forms of address adopted in various situations, intonation features that characterize polite speech, etc. The study of 
speech etiquette occupies a special position at the junction of linguistics, theory and history of culture, ethnography, regional studies, psychology and other humanitarian disciplines. In the broadest sense of the word, speech etiquette characterizes almost any successful act of communication.

Speech etiquette in the narrow sense of the word can be characterized as a system of linguistic means in which etiquette relations are manifested. Elements of this system can be implemented at different language levels:

- At the level of vocabulary and phraseology: special words and fixed expressions, as well as specialized forms of address

- At the grammatical level: using plural for polite treatment; using interrogative sentences instead of imperatives

- At the stylistic level: the requirement for a competent, cultural speech; refusal to use words that directly name obscene and shocking objects and phenomena, the use of euphemisms instead of these words.

- At the intonation level: using polite intonation

At the orthoepy level: using Hello instead of Hello.

- At the organizational and communicative level: a ban on interrupting the interlocutor, interfering in someone else's conversation, etc.

The specificity of speech etiquette is that it characterizes both everyday language practice and language norm. Indeed, elements of speech etiquette are present in the everyday practice of any native speaker (including those with a poor command of the norm), who easily recognizes these formulas in the flow of speech and expects the interlocutor to use them in certain situations.
Elements of speech etiquette are absorbed so deeply that they are perceived by the "naive" linguistic consciousness as part of everyday, natural and regular behavior of people. Ignorance of the requirements of speech etiquette and, as a consequence, their failure to comply (for example, addressing an adult stranger to you) is perceived as a desire to offend or as bad manners.

On the other hand, speech etiquette can be viewed from the point of view of linguistic norms. So, the idea of correct, cultural, normalized speech includes certain ideas about the norm in the field of speech etiquette.

... For example, every native speaker knows the apology formulas for awkwardness; however, some are welcomed by the norm (Excuse me, I beg your pardon) - and others are rejected or not recommended, for example, I apologize (and sometimes "justifications" are given for such a distinction, such as: you cannot excuse yourself, you can only apologize from others, etc.). The very use or non-use of units of speech etiquette can also be the subject of normalization, for example: apology formulas are appropriate if the speaker causes anxiety to his interlocutor, however, one should not apologize too often, as this puts the interlocutor in an awkward position, etc.

... In addition, a violation of the norms and rules of the literary language, especially if it looks like negligence, in itself can be considered a violation of speech etiquette. The border between everyday speech practice and the norm in speech etiquette is inevitably flexible. The practical application of speech etiquette is always somewhat different from the normative models, and not only because of the participants' insufficient knowledge of its rules.

The general principle is that you-forms are used as a sign of respect and greater formality 
of communication; Thou-forms, on the other hand, correspond to informal communication between equals. However, the implementation of this principle can be presented in various versions, depending on how the participants in speech communication are related by age and / or service hierarchy, whether they are in family or friendly relations; on the age and social status of each of them, etc.

\section{CONCLUSION}

Summing up, we can conclude that the ability to clearly, competently and eloquently express their thoughts is absolutely irreplaceable in the modern world. So how to learn to speak beautifully and correctly? To learn how to speak beautifully, politely and competently, one should take an example from the best examples. Read classics, communicate with educated, well-mannered people, go to the theater. And the main thing is to start monitoring your speech right today. After all, the distant ancestors who created our beautiful language are right: the word changes the world around.

\section{REFERENCES}

1. Passov E.l. Communicative method of teaching foreign language speaking. 153 p.

2. Formanovskaya N.I. Speech etiquette and communication culture. Moscow, 1989. 542 p. ed. - Moscow: Education, 1991. 223 p. (Library of a foreign language teacher). - ISBN 5-09-000707-1.

3. Rogova G.V., Rabinovich F.M., Sakharova T.E. Methods of teaching foreign languages in secondary school, 1991. 141 p. 